\title{
Hydrogen Peroxide Catalyst Beds: Lighter and Better Than Liquid Injectors
}

\author{
Eric J Wernimont ${ }^{*}$ \\ General Kinetics Inc., Lake Forest, CA, 92630
}

\begin{abstract}
In the last decade, many parties have become interested in Hydrogen Peroxide for bipropellant applications. Typical bipropellant rocket schemes involve various types of liquidliquid co-injected. Hydrogen peroxide being a monopropellant offers opportunities in that it may be decomposed into superheated steam and oxygen prior to the addition of a fuel. It will be shown that this method has technical advantages over liquid-liquid injection schemes and additionally is lighter in mass.
\end{abstract}

\section{Introduction}

$\mathrm{T}$ HE primary intent of this paper is to show the benefits of using a catalyst bed to decompose hydrogen peroxide (H2O2) in bipropellant systems. In the cases when hydrogen peroxide is selected as an oxidizer there have been two general methods of obtaining combustion with a fuel. The first method (subsequently referred to as staged combustion) is to decompose the hydrogen peroxide in a catalyst bed and then fuel is sprayed into the catalyst bed exhaust products. For most fuels and typical $\mathrm{H} 2 \mathrm{O} 2$ concentrations the decomposed products (oxygen and superheated steam at approximately $1400 \mathrm{~F}$ and $1750 \mathrm{~F}$ for $90 \%$ and $98 \%$ by weight) spontaneously ignite the fuel. Hence in the combustion chamber no separate igniter is required and the liquid (typically) fuel is injected into a gas stream. Figure 1 shows an example of a staged combustion engine (Gamma I), used by the UK, wherein all of the $\mathrm{H} 2 \mathrm{O} 2$ is flown thru the axial flow silver gauze catalbed and fuel is injected down the center-post and then out radial. The second method (subsequently referred to as liquid-liquid) is to co-inject liquid hydrogen peroxide with a liquid fuel. In order to achieve combustion the liquid fuel must be hypergolic with $\mathrm{H} 2 \mathrm{O} 2$ or contain a catalyst. In this method monopropellant (although requiring two fluid systems) performance may be achieved by injecting a catalyst in water. Figure 2 shows a typical liquid-liquid injector.

It will be shown that the catalyst bed based system is superior in three significant respects:

1) Reliability/Safety

2) Performance

3) Reduced Powerhead Mass

\section{Safety \& Reliability Considerations}

The differences between the two types of systems in terms of safety and reliability are primarily a consideration of the transient conditions. Achieving ignition is one of the most important of those transient conditions. In this section it will be shown that all historical systems either began or migrated to the use of a catalyst bed for decomposition of all of the hydrogen peroxide. Hence the historical lesson learned is to always use a catalyst bed for safety and reliability considerations. Present day systems will be discussed and because most of the programs are at present developmental no firm conclusion is made. However, it still seems that the use of catalyst bed is highly desirable. In the sections below these programs as well as some program specific conclusions will be discussed in further detail.

* Chief Operating Officer, 22661 Lambert St, Suite 205, AIAA Member.

Copyright 2005 by General Kinetics Inc. Published by the American Institute of Aeronautics and Astronautics, Inc., with permission. 


\section{A. Historical Applications (H2O2 Usage Prior to 1990's ${ }^{1}$ )}

During World War II and into the early 1950's a dry catalyst bed (typically a stack of silver based gauze) had yet to be invented and practical ${ }^{3}$. As such much of the German work during WWII centered on liquid-liquid systems either co-injecting $\mathrm{H} 2 \mathrm{O} 2$ with a catalytic stream or a hypergolic one. The Germans were able to get these systems to work but definitely understood the advantages a catalyst bed could achieve in terms of system fluid reduction and reliability. There was some work associated with the use of pellet catalyst beds in which pellets were soaked in the preferred permanganate solution (Calcium or Potassium) and then dried. This found use late in the war in submarine development and later in the early American manned space exploration vehicles ${ }^{1}$. This type of a system suffered from pellet breakup for $\mathrm{H} 2 \mathrm{O} 2$ concentrations over $80 \%$. After the war the $\mathrm{H} 2 \mathrm{O} 2$ experience went with the German scientist to Russia, US and England. The Russian experience is still fairly unknown and will not be addressed.

The UK experience was that liquid-liquid systems (with hypergolic fuel) required several design iterations during development to solve hard starts during ignition ${ }^{2}$. As noted in table 1, Harlow states that during 1952 the British decided the best method was to decompose all of the $\mathrm{H} 2 \mathrm{O} 2$ thru a catalyst bed. This statement is further supported by the fact that not only the Gamma I-IV engines used catalyst gauze but also all subsequent $\mathrm{H} 2 \mathrm{O} 2$ engines (Spectre, Stentor, Double Spectre \& Larch) ${ }^{3}$.

Table 1 Quotes for Staged Combustion versus Liquid-Liquid H2O2 Decomposition-Combustion

\begin{tabular}{|l|l|l|}
\hline Author & Program(s) & Quote \\
\hline Harlow $^{4}$ & Gamma I-IV & $\begin{array}{l}\text { "By the beginning of 1952, it had been decided that the increase } \\
\text { in safety and reliability of an engine for manned application was } \\
\text { worth any mass and size penalties associated with passing all the } \\
\text { HP flow thru the catalyst pack." }\end{array}$ \\
\hline Huzel \& Huang & Rocketdyne AR & $\begin{array}{l}\text { “...such a system offers versatility, storability, and simplicity, } \\
\text { including the capability of throttling to low levels and } \\
\text { restartability." In reference to staged combustion. }\end{array}$ \\
\hline Schumb, et al ${ }^{6}$ & General Comment & $\begin{array}{l}\text { "The latter is more simple mechanically but may offer problems } \\
\text { in insuring ignition and smooth and complete combustion.” In } \\
\text { reference to liquid-liquid combustion. }\end{array}$ \\
\hline Kit \& Evered $^{18}$ & General Comment & $\begin{array}{l}\text { "Probably the most reliable, and hence the safest, technique was } \\
\text { to decompose part or all of the peroxide in a separate catalyst } \\
\text { chamber, lead the hot products into the main chamber, and inject } \\
\text { the fuel.” }\end{array}$ \\
\hline
\end{tabular}

The US experience was very similar to that in the UK and although there was some experimentation with liquidliquid systems eventually there was general agreement that decomposition of all of the $\mathrm{H} 2 \mathrm{O} 2$ in staged combustion was the safest and most reliable (see table 1). Hence less than a decade after the practical discovery of silver based catalyst beds they would become the de facto method of $\mathrm{H} 2 \mathrm{O} 2$ decomposition for both monopropellant and bipropellant rocket engines. This included all the propulsion engine manufacturers that fielded $\mathrm{H} 2 \mathrm{O} 2$ systems: GE, Reaction Motors, Walter-Kiddie, Bell \& Rocketdyne.

Hence the method of H2O2 decomposition for bi-propellant applications had gone thru an evolution and all parties had concluded that the staged combustion (catalysts bed decomposition of the H2O2) method was the method which proved the safest and the most reliable. This conclusion would remain until $\mathrm{H} 2 \mathrm{O} 2$ was no longer used in the mid 1980's due to displacement by hydrazine systems for the slight performance gains.

\section{B. Present Applications}

In the 1990's began a renewed interest in $\mathrm{H} 2 \mathrm{O} 2$ for propulsion and power. In the last decade several bipropellant systems have been under development. Table 2 summaries these systems and shows some relevant information. As can be seen from table 2 the method chosen is a combination of the prior methods investigated. Some investigators are reevaluating the liquid-liquid option. Although this runs counter to the lesson learned from prior history (prior section) many investigators incorrectly assume that the powerhead mass may be reduced by elimination of the catalyst bed (discussed below). Additionally, new materials (catalyst) or analytic tools seem to show that liquid-liquid systems may have an advantage. In fact the author began his $\mathrm{H} 2 \mathrm{O} 2$ combustion experience 
in 1990 with a liquid-liquid injector which ended in some deformed hardware. This caused the author to seek catalyst bed solutions just as the prior investigators had done many years prior. This is not to say that liquid-liquid systems don't work it is just that they are harder to develop and less deterministic in operation. Because most of the recent liquid-liquid research is International Traffic in Arms Regulations (ITAR) restricted a modern consensus as not been reached as to the viability of replacing staged combustion as the preferred method.

Table 2 Recent Bi-Propellant Programs and Method of H2O2 Decomposition

\begin{tabular}{|l|l|l|l|}
\hline Program & Company & Method & Comments \\
\hline USFE & OSC & Staged Combustion & No Ignition Anomalies \\
\hline SLI Hypergolic Injector & Rocketdyne & Liquid-Liquid & ITAR Restricted \\
\hline ARRE & Aerojet & Liquid-Liquid-Gas & ITAR Restricted \\
\hline BA-810 & Beal Aerospace & Proprietary & Proprietary \\
\hline Navy 300 lbf Prototype & China Lake, CA & Liquid-Liquid & Some Ignition High Pressure Spikes \\
\hline LBTS - Subscale & NGST & Staged Combustion & Smooth Ignition Noted \\
\hline
\end{tabular}

\section{Performance Considerations}

The use of a catalyst bed to decompose all of the hydrogen peroxide (staged combustion) has several distinct performance advantages over the liquid-liquid systems. One major advantage is that the oxidizer is injected into the combustion chamber in the form of gas. Hence when the liquid fuel is injected this provides for excellent atomization and mixing ${ }^{15}$ which produces higher combustion efficiency for shorter $\mathrm{L}^{*}$. Or in other words there is less combustion chamber mass (because it is shorter) for the same level of combustion efficiency versus a liquidliquid system. This is especially true for most H2O2-hydrocarbon combinations because they usually optimize at high oxidizer to fuel ratios (4-8).

Other features which may be of interest is the fact that the motor can operate in monopropellant mode alone (roughly 50\% of the performance in bi-propellant mode) which in some cases provides for rapid throttling. Typically a motor would be started in monopropellant mode and the operational health could be monitored (via measured chamber pressure) before committing to bi-propellant (fuel on) operation. This further provides an excellent step in development programs in that one can solve half (actually more since the oxidizer to fuel ratio is usually large) of the combustion problem separately. Counter to this a liquid-liquid (possibly hypergolic) in which all the timing, etc has to be just right or explosive results may be the consequence.

Additionally, the use of a catalyst bed provides for power which may be used for auxiliary purposes. Chief amongst these is to use the decomposed hydrogen peroxide products to drive a pump for the fuel and the oxidizer before it is then dumped into the combustion chamber. A perfect example of this is the use of the full oxidized flow driving the turbine (relatively large diameter, low rpm) in the LR-40 (also known as the super performing engine built by Reaction Motors). This provides for a more mass efficient and compact system, see reference 16 for further details.

Recent experimental data with a $250 \mathrm{lbf}$ vacuum engine has shown that ignition times $(0-90 \%$ of mean chamber pressure) of 20 msec have been achieved with a staged combustion system ${ }^{17}$ which is comparable to conventional hypergolic systems. The 20 msec ignition time was achieved using 90\% H2O2 and RP-1. It is expected that use of $98 \% \mathrm{H} 2 \mathrm{O} 2$ and a lower vapor pressure fuel would further shorten this time.

\section{Powerhead Mass Flow Rate per Unit Mass Considerations}

For comparison of the relative merits on a mass basis for catalyst bed stage combustion versus liquid-liquid hypergolic systems only recent activities will be considered. It is worthy to note however that reference 4 states that the decision to add a catalyst bed for full oxidizer flow decomposition only added $7 \%$ to the mass of the powerhead (the power head defined for our purposes being everything downstream of the oxidizer and fuel fire valves less the combustion chamber). This was with a catalyst bed flux of no more than $0.4 \mathrm{lbm} /\left(\mathrm{in}^{\wedge} 2\right.$-s) in an approximately 1800 lbf thrust engine. Further the parameter of mass flow rate thru the powerhead over mass of the powerhead will be considered the figure of merit. This parameter is similar to a thrust to weight ratio without the effects of expansion and expansion ratio.

For the liquid-liquid hypergolic system the recent work by Rocketdyne (SLI hypergolic injector) will be used as described in references 8 and 9 which is a static test version of an approximately 10,000 lbf vacuum engine. Figure 3 shows a cutaway of a solid model of this test article taken from reference 9 . The performance parameters were taken from reference 8 and a throat diameter was back calculated assuming 100\% combustion efficiency. The 
calculated throat diameter is then used to provide dimensional scaling factors for figure 3 . The powerhead mass is then (assuming stainless steel density) assumed to be the volume associated with the oxidizer inlet flange diameter by the length of the fuel manifold and oxidizer inlet flange. The mass number comes out to be around $75 \mathrm{lbm}$ with a corresponding total mass flow of around $31 \mathrm{lbm} / \mathrm{s}$ gives a power head mass flow rate per unit mass of approximately $0.4 \mathrm{lbm} / \mathrm{s} / \mathrm{lbm}$.

For the state of the art catalyst bed staged combustion rocket engine the General Kinetics Inc. $300 \mathrm{lbf}$ vacuum rocket engine is used for comparison (shown in figure 4). This engine is a further refinement of the engine tested in the fall of 2003 and documented in reference 17. The engine structure is designed using boiler code stress criteria so comparison to the Rocketdyne hypergolic injector is reasonable. For this engine the powerhead mass flow rate per unit mass is $1.0 \mathrm{lbm} / \mathrm{s} / \mathrm{lbm}$. It is worthy to note that should this motor be allowed to operate at the 1500 psia chamber pressure of the Rocketdyne engine the figure of merit raises to $1.5 \mathrm{lbm} / \mathrm{s} / \mathrm{lbm}$. This is because the catalyst bed flux can be increased to the maximum tested by General Kinetics Inc of $1.4 \mathrm{lbm} /(\mathrm{in} \wedge 2-\mathrm{s}){ }^{19}$. Further gains are expected once testing at higher mass fluxes has been conducted.

Hence, given the state of the art in catalyst bed technology the staged combustion system is not only better from a safety, reliability and performance perspective but is also provides for a lighter system by a factor of 2.5. Additionally at higher chamber pressures higher fluxes are permitted resulting in a lighter system (compared to liquid-liquid) by a factor of over 3.5 times. These results are shown below in table 3 .

Table 3 Relative Comparison of Different H2O2 Bi-Propellant Powerhead Configurations

\begin{tabular}{|l|l|l|}
\hline System & $\begin{array}{l}\text { Powerhead Mass Flow per } \\
\text { Unit Mass (lbm/s)/(lbm) }\end{array}$ & Lighter by Factor \\
\hline $\begin{array}{l}\text { Rocketdyne } \\
\text { Hypergolic Injector }\end{array}$ & 0.4 & 1.0 \\
\hline General Kinetics Inc. & 1.0 & 2.5 \\
\hline $\begin{array}{l}\text { General Kinetics Inc } \\
\text { Flux }=1.4 \mathrm{lbm} /(\mathrm{in} \wedge 2 \text {-s) }\end{array}$ & 1.5 & 3.75 \\
\hline
\end{tabular}

\section{Conclusions}

Test data, test observation, historical lessons learned and recent state of the art technology have been collected and reviewed to examine the differences between $\mathrm{H} 2 \mathrm{O} 2$ - hydrocarbon fuel combustion methods using the two primary methods of achieving ignition. Those two methods are catalyst bed staged combustion and liquid-liquid hypergolic (or catalytic) combustion. It has been shown that the catalyst bed staged combustion is superior for several reasons:

- Historical engine developers unanimously concluded that the catalyst staged combustion was more reliable and safer.

- Use of gas on liquid injection which results from catalytic staged combustion provides for better mixing and combustion efficiency for a given L*.

- Use of state of the art catalyst bed systems at chamber pressures of 1500 psia results in a powerhead weight reduction factor of at least 3.5 .

\section{References}

\footnotetext{
${ }^{1}$ Wernimont, E., Ventura, M., Garboden, G., and Mullens, P., “Past and Present Uses of Rocket Grade Hydrogen Peroxide,” $2^{\text {nd }}$ International Hydrogen Peroxide Propulsion Conference, Purdue University, Nov 7-10, 1999, pp. 45-67.

${ }^{2}$ Harlow, J., “Alpha, Beta and RTV-1, The Development of Early British Liquid Propellant Rocket Engines," $44^{\text {th }}$ Congress of the International Astronautical Federation, IAA93-676, Graz, Austria, October 16-22, 1993.

${ }^{3}$ Millward, Douglas, The Black Arrow Rocket - A history of a satellite launch vehicle and its engines, $1^{\text {st }}$ ed, NMSI Trading Ltd, Science Museum, Exhibition Road, London SW7 2DD, 2001.

${ }^{4}$ Harlow, John, "Hydrogen Peroxide Engines - Early Work on Thermal Ignition at Westcott," $2^{\text {nd }}$ International Hydrogen Peroxide Propulsion Conference, Purdue University, Nov 7-10, 1999, pp. 211-219.

${ }^{5}$ Huzel, Dieter K. and Huang, David H., Modern Engineering For Design of Liquid-Propellant Rocket Engines, 2nd ed, Vol 147 Progress in Astronautics and Aeronautics, AIAA, Washington DC, 1992.
} 
${ }^{6}$ Schumb, Walter C., Satterfield, Charles N., and Wentworth, Ralph L., Hydrogen Peroxide, $1^{\text {st }}$ ed, Reinhold Publishing Corp, New York, NY, 1955, pp. 601.

${ }^{7}$ Clark, John D., Ignition! An Informal History of Liquid Rocket Propellants, Rutgers University Pres, New Brunswick, New Jersey, 1972.

${ }^{8}$ McNeal, Curtis I., and Anderson, William E. “The Peroxide Pathway,” $2^{\text {nd }}$ International Hydrogen Peroxide Propulsion Conference, Purdue University, Nov 7-10, 1999, pp. 211-219.

${ }^{9}$ Unger, Ronald J., "NASA Hydrogen Peroxide Propulsion Perspective," $5^{\text {th }}$ International Hydrogen Peroxide Propulsion Conference, Purdue University, Sept 15-19, 2002, pp. 245-255.

${ }^{10}$ Aerojet Press Release, “Aerojet Validates Unique Tri-Fluid Injector for Air Force Advanced Reusable Rocket Engine”, URL: http://www.aerojet.com/program/news/nr_041002_aerojet_validates_unique_trifluid_injector_for_af_arre.htm [cited July 06, 2005], April 10, 2002.

${ }^{11}$ Beal Aerospace Press Release, “Beal Aerospace Fires Largest Liquid Rocket Engine in 30 Years”, URL: http://www.bealaerospace.com/press.htm [cited July 06, 2005], March 04, 2000.

${ }^{12}$ Purcell, Nick, Diede, Amos and Minthorn, Martin, "Test Results of New Reduced-Toxicity Hypergols for Use With Hydrogen Peroxide Oxidizers," $5^{\text {th }}$ International Hydrogen Peroxide Propulsion Conference, Purdue University, Sept 15-19, 2002, pp. 111-122.

${ }^{13}$ Muss, Jeffry A., Johnson, Curtis W., Kruse, William and Cohn, Richard K., “The Performance of Hydrogen Peroxide Fuels with H2O2 in a Uni-Element Combustor," $39^{\text {th }}$ AIAA Joint Propulsion Conference and Exhibit, AIAA-2003-4623, Huntsville, AL, 2003.

${ }^{14}$ Millard, Douglas and Harlow, John, “Gamma I and the UK’s First Manned Rocket Interceptor”, unpublished, Authors are Chair of British Interplanetary Society History Committee and President British Interplanetary Society.

${ }^{15}$ NASA, Liquid Rocket Engine Injectors, NASA Space Vehicle Design Criteria (Chemical Propulsion), NASA SP-8089, March 1976.

${ }^{16}$ Ventura, Mark C. and Wernimont, Eric J., "History of the Reaction Motors Super Performance 90 Percent H2O2/Kerosene LR-40 Rocket Engine,” 37th AIAA Joint Propulsion Conference and Exhibit, AIAA-2001-3838, Salt Lake, UT, 2001.

${ }^{17}$ Wernimont, Eric J. and Durant, D., "Development of a $250 \mathrm{lbfv}$ Kerosene - 90\% Hydrogen Peroxide Thruster," $40^{\text {th }}$ AIAA Joint Propulsion Conference and Exhibit, AIAA-2004-4148, Fort Lauderdale, FL, 2004.

${ }^{18}$ Kit, Boris, and Evered, Douglas S., Rocket Propellant Handbook, $1^{\text {st }}$ ed, The Macmillan Company, New York, NY, 1960.

${ }^{19}$ Wernimont, Eric J. and Durant, D., "State of the Art High Performance Hydrogen Peroxide Catalyst Beds," $40^{\text {th }}$ AIAA Joint Propulsion Conference and Exhibit, AIAA-2004-4148, Fort Lauderdale, FL, 2004. 


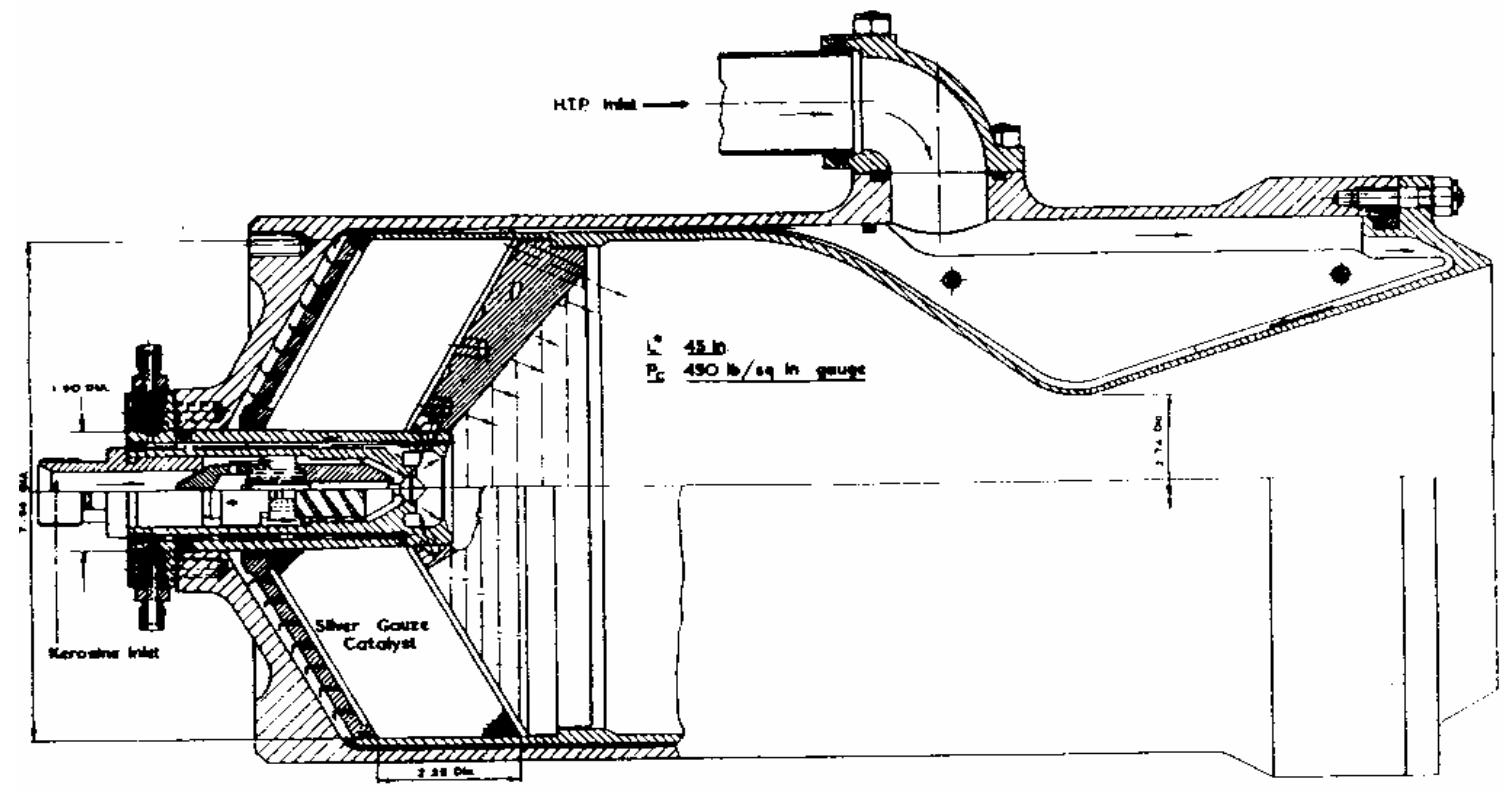

Figure 1. Cutaway View of Gamma I Engine Showing Catalyst Bed Staged Combustion with Full Oxidizer Flow Decomposition with Gauze Catalyst and Liquid Fuel Injected Down Centerpost and Radial Flow Into Combustion Chamber ${ }^{14}$
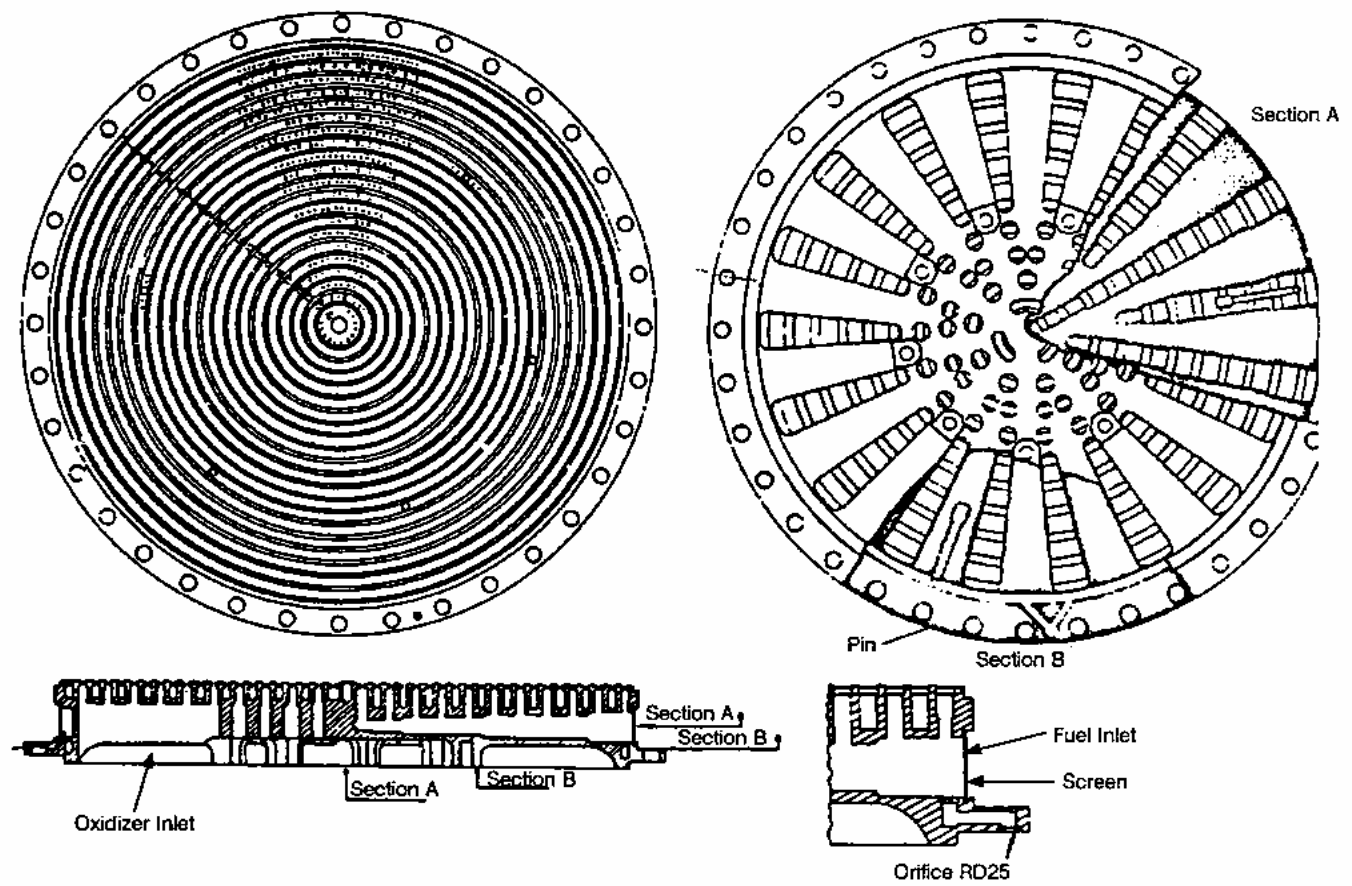

Figure 2. End View and Section Views of Typical Liquid-Liquid Injector ${ }^{5}$ 


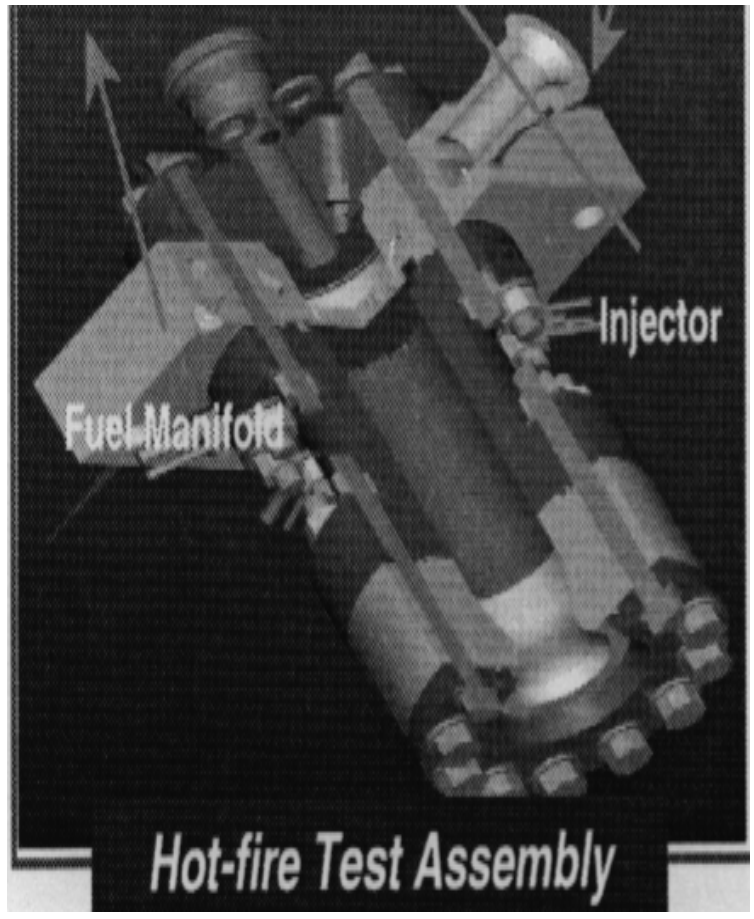

Figure 3. Cutaway View of Rocketdyne Hypergolic Injector Test Article for Approximately 10k lbf 98\% H2O2-Kerosene Rocket Engine

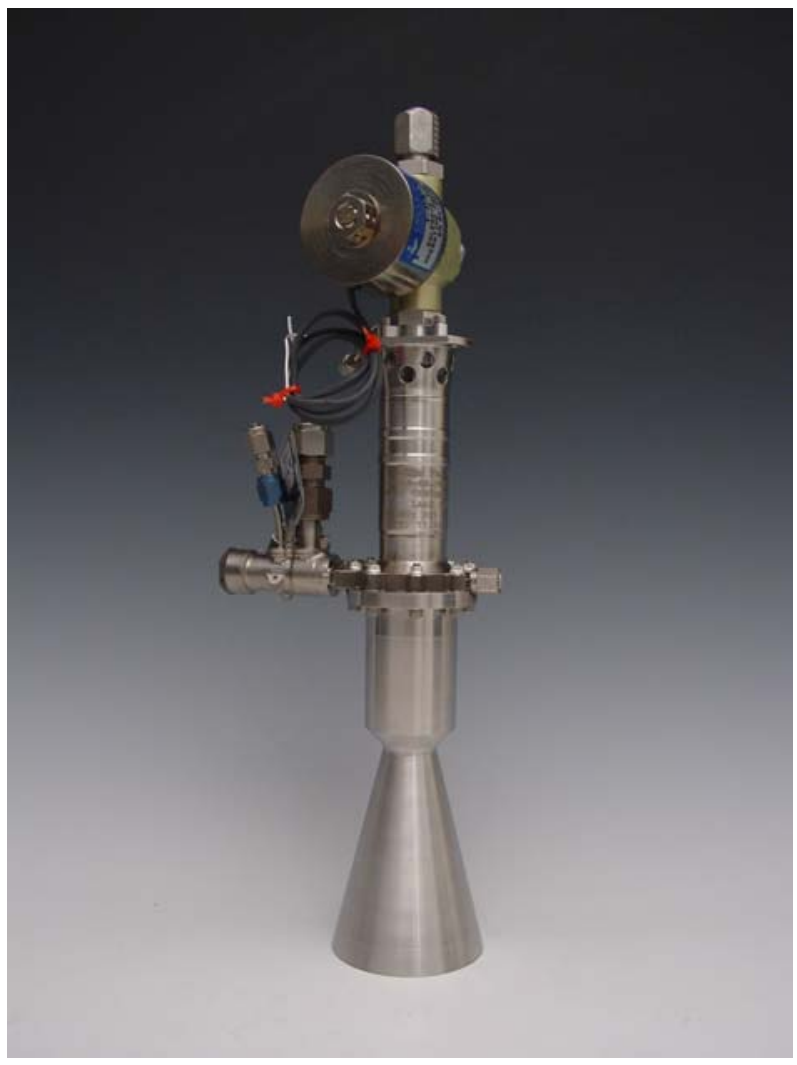

Figure 4. General Kinetics Inc. State of the Art 300 lbf Vacuum 90\% H2O2 - RP-1 Rocket Engine 